\title{
Development and Validation of Reverse Phase HPLC Method for Simultaneous Estimation of Allopurinol and Lesinurad in its API and Pharmaceutical Dosage Form
}

\author{
Sayma Khader*, Ayesha Begum K, D. Ramakrishna
}

Department of Pharmaceutical Analysis and Quality Assurance, ShadanWomens College of Pharmacy, Hyderabad.

\begin{abstract}
A new, reliable, and validated reverse phase-high-performance liquid chromatography (HPLC) method was developed to quantify the amount of allopurinol and lesinurad simultaneously in solid (tablet) dosage form. A clear chromatographic division was attained on inertsil ODS $(4.6 \times 250 \mathrm{~mm}, 5 \mathrm{~mm})$ column, and a mixture of $0.1 \%$ trifluoroacetic acid and methanol in the ratio of $40: 60 \mathrm{v} / \mathrm{v}$ was used as mobile phase. The rate of flow was set at $1 \mathrm{~mL} / \mathrm{min}$, and UV detection was achieved at $\lambda_{\max }$ of $255 \mathrm{~nm}$. Injection volume was set to $20 \mu \mathrm{L}$. The correlation coefficient of 0.999 was established, and the accurateness was found to be 100.69 and 100.49 for both the drugs, respectively. Therefore, the developed method was simple, specific, precise, and stable. Hence, the method can be employed to estimate the said drugs in other pharmaceutical formulations.
\end{abstract}

Keywords: Allopurinol, Degradation studies, HPLC, Lesinurad, Vaccum freeze, Validation.

\section{INTRODUCTION}

Allopurinol $\left(\mathrm{C}_{5} \mathrm{H}_{4} \mathrm{~N}_{4} \mathrm{O}\right)$ is a xanthine oxidase inhibitor that inhibits the synthesis of uric acid in certain conditions like gout and kidney diseases. It is considered as a standard treatment for hyperuricemia. It possesses a purine skeleton, which is structurally an isomer of a natural purine base, hypoxanthine and inhibits xanthine oxidase enzyme, which oxidizes hypoxanthine to xanthine (Arellano et al., 1993; Goicoechea et al., 2010). As a result, uric acid production is prevented, which is the desired approach for the treatment of gout. Hence, it is used as an anti-gout agent. It is also used in the case of patients with inflammatory bowel syndrome (Ermer et al., 2001; Stamp, 2014).

Lesinurad $\left(\mathrm{C}_{17} \mathrm{H}_{14} \mathrm{BrN}_{3} \mathrm{O}_{2} \mathrm{~S}\right)$ is a selective uric acid reabsorption inhibitor (SURI) that inhibits URAT1 transporter. URAT1 is responsible for the reabsorption of filtered uric acid from the renal tubular lumen during excretion in kidneys (Hoy, 2016) and is employed for the treatment of gout in combination with allopurinol, a hypoxanthine isomer that inhibits xanthine oxidase enzyme. It also inhibits OAT4, which is URAT protein that leads to diuretic-induced hyperuricemia (Borstad et al., 2014; Perez-Ruiz et al., 2016; Bardin et al., 2017). Duzallo was the first drug consists of the mixture of allopurinol and lesinurad, for the treatment of gout as well as other allied

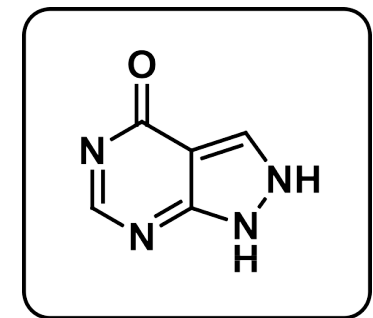

Allopurinol (1, 2 - dihydro - 4H - pyrazolo [3, 4 - d] pyrimidin - 4 - one)

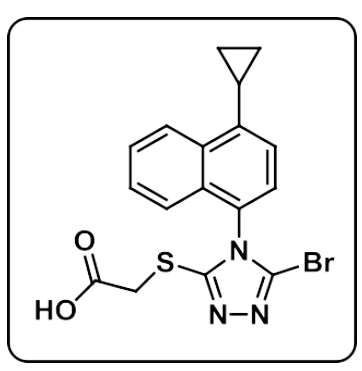

Lesinurad (2 - \{[5 - bromo - 4 - (4 - cyclopropylnaphthalen - 1 yl) $-4 \mathrm{H}-1,2,4-$ triazol $-3-\mathrm{yl}$ ] sulfanyl\} acetic acid)

\section{Corresponding author}

Sayma Khader

Email : sayma.maryam95@gmail.com 
diseases approved by the Food and Drug Administration ( FDA) in 2017.

Literature survey reveals that numerous analytical methods have been accounted for the quantitative and qualitative determination of allopurinol individually in the pharmaceutical formulations and a few methods, in combination with lesinurad after the approval by FDA in 2017 for using HPLC method development (Revathi et al., 2016; Dastiagiriamma et al., 2018). The developed methods were mostly available for allopurinol alone. Few methods were available for quantification of allopurinol in combination with lesinurad (Attia et al., 2018) but, to best our knowledge, a validate RP-HPLC method has not been established yet. Hence the present study reported a simple, reliable, accurate, rapid, and validated RP-HPLC method for the quantification of allopurinol and lesinurad in a combined dosage form.

\section{MATERIALS AND METHODS}

Allopurinol was obtained as a gift sample from Harman Finochem Ltd., Mumbai, and lesinurad was obtained from A. R. Life Sciences Pvt. Ltd., from Hyderabad, India. Potassium dihydrogen phosphate was purchased from Finer Chemical Ltd., Hyderabad, India. HPLC grade acetonitrile and methanol were procured from E-Merck, Hyderabad. All other chemicals and solvents used were of analytical grade.

\subsection{Instruments}

HPLC system (Waters, USA) consisting of empower-II software, quaternary pump, manual rheodyne injector, and photodiode-array detection (PDA) detector was used for analysis. They were processed by using micropipettes made up of borosil, centrifuge, and ultra-sonicator.

\subsection{Optimized Conditions of Chromatography}

$\begin{array}{lll}\text { Instrument } & : & \text { Waters HPLC (2695 separations } \\ & & \text { module) } \\ \text { Temperature } & : & \text { Ambient } \\ \text { Column } & : & \begin{array}{l}\text { Inertsil ODS } \\ (4.6 \times 250 \mathrm{~mm}, 5 \mathrm{~mm})\end{array} \\ \text { Mobile Phase } \quad: & 0.1 \% \text { Trifluoro Acetic Acid buffer } \\ & & \& \text { Methanol }(40: 60) \\ \text { Flow Rate } & : & 1 \mathrm{~mL} / \mathrm{min} \\ \lambda_{\text {max }} & 255 \mathrm{~nm} \\ \text { Injected Volume: } & 20 \mu \mathrm{L} \\ \text { Run time } & : & 10 \mathrm{~min} .\end{array}$

\subsection{Buffer and Mobile Phase Preparation}

\subsubsection{1\% Trifluoro Acetic Acid (TFA)}

Dissolved $1 \mathrm{~mL}$ of trifluro acetic acid in $1000 \mathrm{~mL}$ of HPLC water with a $\mathrm{pH}$ adjusted up to 3.0. The obtained solution was passed through $0.44 \mu \mathrm{m}$ membrane filter and sonicated for ten minutes.

\subsubsection{Mobile Phase Preparation}

$400 \mathrm{~mL}(40 \%)$ of prepared buffer solution was mixed with $600 \mathrm{~mL}(60 \%)$ of Methanol HPLC. By using an ultrasonic water bath, the dissolved gases were removed by degassing for ten minutes and then passed through $0.45 \mu \mathrm{m}$ filter membrane under vacuum filtration. The same was used as diluents (Ahuja \& Rasmussen, 2011; Snyder et al., 2012; Dastiagiriamma et al., 2018).

\subsection{Standard and Sample Solution of Allopurinol and Lesinurad}

\subsubsection{Preparation of Standard Solution}

$0.06 \mathrm{gm}$ of allopurinol and $0.04 \mathrm{gm}$ of lesinurad were weighed accurately and transferred into a 0.1 L dry volumetric flask. A total of $7 \mathrm{~mL}$ of diluents was added to the mixture and sonicated to dissolve the residual particles. Final volume was adjusted by mixing the same solvent (stock solution). $1.5 \mathrm{~mL}$ of the above stock solution was pipetted to $10 \mathrm{~mL}$ volumetric flask, and the final volume was diluted with the diluent.

\subsubsection{Preparation of Sample Solution}

Accurately weighed 10 tablets were crushed in mortar and pestle. An equivalent amount of $0.06 \mathrm{~g}$ of allopurinol and $0.04 \mathrm{~g}$ lesinurad samples were transferred into a $0.1 \mathrm{~L}$ dry volumetric flask add to which $7 \mathrm{~mL}$ of diluent was added and subjected to sonication for $15 \mathrm{~min}$ to dissolve the residue. The final volume was adjusted up to the mark with the same solvent and is passed through $0.45 \mu$ injection filter. $1.5 \mathrm{~mL}$ of allopurinol and lesinurad from the stock solution was taken and pipetted to $10 \mathrm{~mL}$ volumetric flask and diluted. The final volume was made with diluent.

\subsection{Procedure}

The HPLC system was injected with $20 \mu \mathrm{L}$ of the standard, sample and peak areas were measured for allopurinol and lesinurad peaks. The percentage assay was 
calculated by using the following formula, (Ahuja and Dong, 2005; Connors, 2007).

$$
\% \text { Assay }=\frac{\mathrm{AT}}{\mathrm{AS}} * \frac{\mathrm{WS}}{\mathrm{DS}} * \frac{\mathrm{DT}}{\mathrm{WT}} * \frac{\mathrm{Avg} \cdot \mathrm{wt} .}{\text { Label claim }} * \frac{\mathrm{p}}{100} * 100
$$

Where, AT =Average area count of sample

$$
\begin{aligned}
& \text { AS }=\text { Average area count of standard } \\
& \text { WS }=\text { Weight of working standard }(\mathrm{mg}) \\
& \mathrm{P} \quad=\% \text { purity }
\end{aligned}
$$

\subsection{Method Validation}

The present analytical method was validated as per ICH guidelines with reverence to various parameters like linearity, precision, specificity and accuracy, limit of detection (LOD), limit of quantitation (LOQ) and robustness (Bakshi \& Singh, 2002; Breaux et al., 2003; Swartz and Krull, 2018).

\subsubsection{System Suitability}

The prepared standard solutions were injected into the HPLC chromatographic system and evaluated for various parameters such as theoretical plates, tailing factor, retention time resolution, and asymmetric factor. The results are given in Table 1.

\subsubsection{Assay}

$20 \mu \mathrm{l}$ of the sample and standard solutions were injected separately into the HPLC system and the peak areas were measured. The percentage quantity of both the drugs was then calculated and reported in Table 2.

\subsubsection{Precision}

Equivalent concentration solutions of allopurinol and lesinurad were injected six times, and \% RSD was determined for both the drugs.

\subsubsection{Ruggedness}

The ruggedness was determined by measuring the analyst to analyst variation assay of two different analysts.

\subsubsection{Accuracy}

The accuracy of the developed method was done by recovery studies by the addition of standard drug solution to pre-analyzed sample solution at three different levels 50, 100, and 150\%. The percentage recovery and percentage mean recovery were determined for the drugs and shown in Table 7.

\subsubsection{Limit of Detection (LOD)}

$$
\operatorname{LOD}=\frac{3 \sigma}{\mathrm{S}}
$$

Where, $\sigma=$ standard deviation of the response $\mathrm{S}=$ slope of the calibration curve

\subsubsection{Limit of Quantification (LOQ)}

$$
\text { LOD }=\frac{10 \sigma}{S}
$$

Where, $\sigma=$ standard deviation of the response $\mathrm{S}=$ slope of the calibration curve

\subsubsection{Robustness}

Robustness is done by changing the flow rate and the organic phase of the mobile phase.

\subsection{Degradation Studies}

\subsubsection{Hydrolytic Degradation (Acidic condition)}

Stock solution measuring $1.5 \mathrm{~mL}$ was pipetted to $10 \mathrm{~mL}$ volumetric flask, and $3 \mathrm{~mL}$ of $0.1 \mathrm{~N} \mathrm{HCl}$ was added. Then, the volumetric flask was maintained at $60^{\circ} \mathrm{C}$ for 24 hours followed by neutralizing using $0.1 \mathrm{~N} \mathrm{NaOH}$. The final volume was adjusted to $10 \mathrm{~mL}$ with diluents, which was then filtered and stored in vials.

\subsection{Hydrolytic Degradation (Alkaline condition)}

Stock solution measuring $1.5 \mathrm{~mL}$ was pipetted to $10 \mathrm{~mL}$ volumetric flask, and $3 \mathrm{~mL}$ of $0.1 \mathrm{~N} \mathrm{NaOH}$ was added. Then, the volumetric was maintained at $60^{\circ} \mathrm{C}$ for 24 hours, followed by neutralizing using $0.1 \mathrm{~N} \mathrm{HCl}$. The final volume was adjusted to $10 \mathrm{~mL}$ with diluent. The solution was filtered and place in vials (Blessy et al., 2014).

\subsubsection{Thermal Induced Degradation}

Allopurinol and lesinurad sample was kept in a Petri dish and placed in a hot air oven maintained at $110{ }^{\circ} \mathrm{C}$ for 3 hours. The samples were then diluted with the diluents, injected into HPLC and analyzed.

\subsubsection{Degradation due to Oxidation}

Stock solution measuring $1.5 \mathrm{~mL}$ was pipetted to $10 \mathrm{~mL}$ volumetric flask and $1 \mathrm{~mL}$ of $12.5 \% \mathrm{w} / \mathrm{v}$ of $\mathrm{H}_{2} \mathrm{O}_{2}$ was added. The final volume was adjusted to the mark with diluent. The volumetric flask was kept at room temperature for 15 minutes, and the solution was subjected to filtration followed by placing in vials. 


\subsubsection{Photo Degradation}

Stock solution measuring $1.5 \mathrm{~mL}$ was pipetted to $10 \mathrm{~mL}$ volumetric flask and exposed to sunlight for $24 \mathrm{hrs}$. The final volume was made up with the diluents till the mark. The solution was filtered with 0.45 microns syringe filters and transferred in vials (Reynolds et al., 2002; Ngwa, 2010; Baertschi et al., 2016).

\section{RESULTS}

\subsection{System Suitability}

It was found from the obtained data that all the system suitability parameters such as retention time, resolution, tailing, and plate count have shown uniformity and was within the limit. The results are tabulated, and from the observed data, it can be concluded that the system was suitable for analysis.

\subsection{Assay}

Standard and sample solution injected as described under experimental work. The percentage of the assay was found to be 100.87 and 100.18 . The corresponding results are shown in Table 2.

\subsection{Validation Parameters}

\subsubsection{Linearity}

Linearity was found in the range of $30-150 \mu \mathrm{g} / \mathrm{mL}$ for allopurinol and $20-100 \mu \mathrm{g} / \mathrm{mL}$ for lesinurad with a linearity correlation coefficient of 0.999 and 0.999 which shows

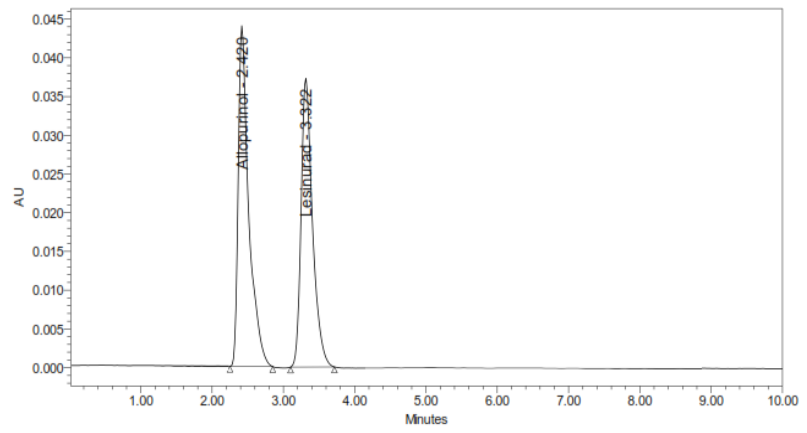

Fig. 1: Chromatogram of system suitability for allopurinol and lesinurad

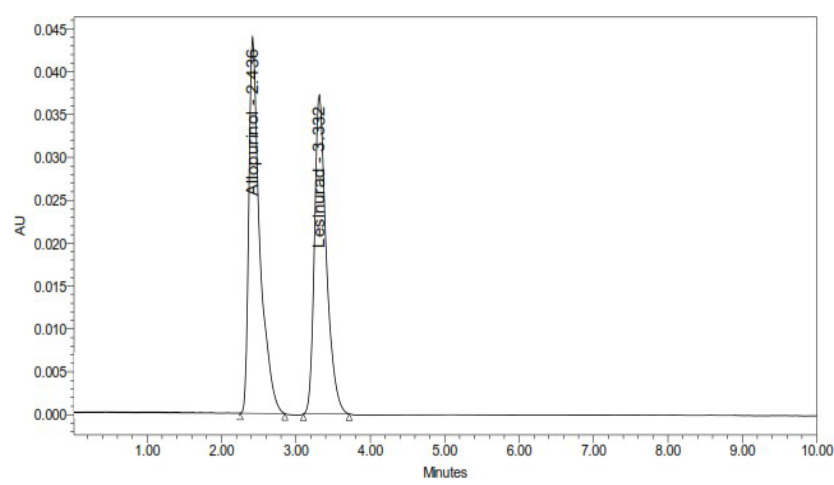

Fig. 2: Chromatogram for standard allopurinol and lesinurad

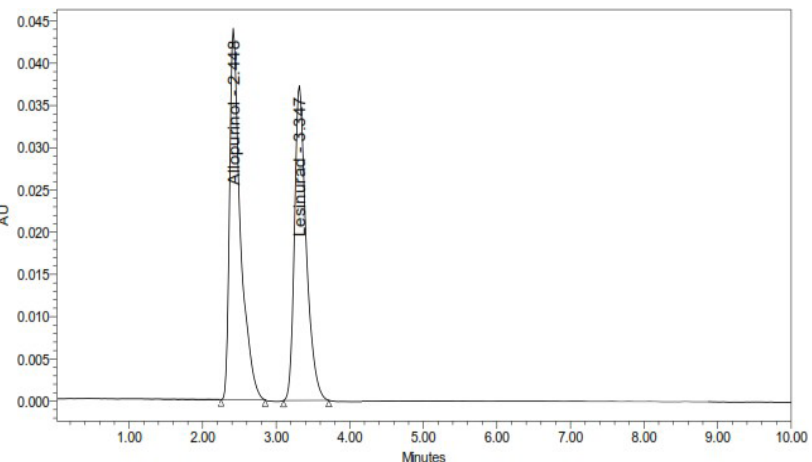

Fig. 3: Chromatogram for sample allopurinol and lesinurad

Table 1: System suitability parameters for allopurinol and lesinurad

\begin{tabular}{|c|c|c|c|c|c|c|c|}
\hline S. No. & Name & $R T(\min )$ & $\begin{array}{l}\text { Area } \quad(\mu V \\
\text { sec) }\end{array}$ & Height $(\mu V)$ & USP resolution & USP tailing & $\begin{array}{l}\text { USP plate } \\
\text { count }\end{array}$ \\
\hline 1 & Allopurinol & 2.420 & 466482 & 43853 & 3.16 & 1.53 & 3467.19 \\
\hline 2 & Lesinurad & 3.322 & 371997 & 37483 & 3.16 & 1.40 & 5115.36 \\
\hline \multicolumn{8}{|c|}{ Table 2: Assay results of allopurinol and lesinurad } \\
\hline Name & & \multicolumn{3}{|c|}{ Claim of label (mg) } & \multicolumn{2}{|r|}{$\%$ Assay } & \\
\hline \multicolumn{2}{|c|}{ Allopurinol } & \multicolumn{3}{|c|}{300} & \multicolumn{2}{|r|}{100.87} & \\
\hline \multicolumn{2}{|c|}{ Lesinurad } & \multicolumn{3}{|c|}{200} & \multicolumn{2}{|r|}{100.18} & \\
\hline
\end{tabular}

Table 3: Linearity results of allopurinol and lesinurad

\begin{tabular}{lllll}
\hline & Allopurinol & \multicolumn{3}{l}{ Lesinurad } \\
\cline { 2 - 5 } S. No. & Concentration of solution $(\mu \mathrm{g} / \mathrm{mL})$ & Peak area & Concentration of solution $(\mu \mathrm{g} / \mathrm{mL})$ & Peak area \\
\hline 1 & 30 & 158922 & 20 & 125433 \\
2 & 60 & 319278 & 40 & 254978 \\
3 & 90 & 467255 & 60 & 369727 \\
4 & 120 & 642988 & 80 & 503762 \\
5 & 150 & 783655 & 100 & 623994 \\
\hline
\end{tabular}


that the method is capable of producing good sensitivity and useful for routine analysis (Table 3 and Table 4).

\subsubsection{Precision}

For the present developed RP-HPLC method, the precision was determined by using quality control samples. The method show precision of 0.5 and 0.8 , indicating the method was precise when performed on different days also. The percentage of relative standard deviation (RSD) was reported in Table 5.

\subsubsection{Ruggedness}

There was no significant change in assay content and system suitability parameters at different conditions of ruggedness like day to day and system to system variation. The method show ruggedness of 0.5 and 0.5 , which reveals that the method is precise. The percentage of relative standard deviation (RSD) was reported in Table 6.

Table 4: Analytical performance parameters of allopurinol and lesinurad

\begin{tabular}{lll}
\hline Parameters & Allopurinol & Lesinurad \\
\hline Slope $(\mathrm{m})$ & 5255.7 & 6242.4 \\
Intercept $(\mathrm{c})$ & 1174.7 & 860.48 \\
Correlation coefficient $\left(\mathrm{R}^{2}\right)$ & 0.999 & 0.999 \\
\hline
\end{tabular}

Table 5: Precision results of allopurinol and lesinurad

\begin{tabular}{lll}
\hline Injection & $\begin{array}{l}\text { Peak area } \\
\text { (Allopurinol) }\end{array}$ & $\begin{array}{l}\text { Peak area } \\
\text { (Lesinurad) }\end{array}$ \\
\hline 1 & 468873 & 362588 \\
2 & 465388 & 370267 \\
3 & 468873 & 370468 \\
4 & 463548 & 368962 \\
5 & 467126 & 370882 \\
6 & 469978 & 369764 \\
Average & 467297.7 & 368821.8 \\
Standard deviation & 2444.7 & 3124.4 \\
$\%$ RSD & 0.5 & 0.8 \\
\hline
\end{tabular}

Table 6: Ruggedness Results of Allopurinol and Lesinurad

\begin{tabular}{lll}
\hline Injection & $\begin{array}{l}\text { Peak area } \\
\text { (Allopurinol) }\end{array}$ & $\begin{array}{l}\text { Peak area } \\
\text { (Lesinurad) }\end{array}$ \\
\hline 1 & 462866 & 370757 \\
2 & 469272 & 368674 \\
3 & 463875 & 368562 \\
4 & 465887 & 365298 \\
5 & 463867 & 367744 \\
6 & 465387 & 369977 \\
Average & 465192.3 & 368502.0 \\
Standard deviation & 2283.3 & 1904.4 \\
\%RSD & 0.5 & 0.5 \\
\hline
\end{tabular}

\subsubsection{Accuracy}

The total recovery was found to be 100.69 and $100.49 \%$ for allopurinol and lesinurad. The validation of the developed method shows that the accuracy is well within limits (Table 7).

\subsubsection{Limit of Detection (LOD)}

The LOD for allopurinol and lesinurad were found to be 3.03 and 2.98, which is in acceptance criteria given in Table 8.

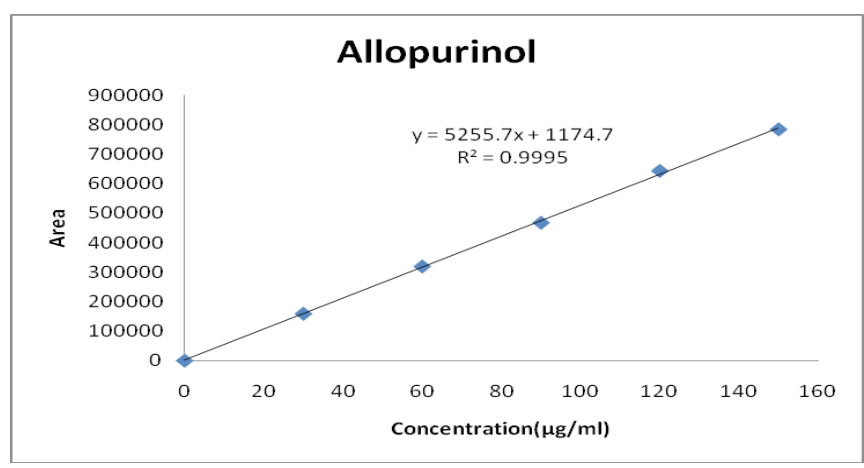

Fig. 4: Calibration graph for allopurinol

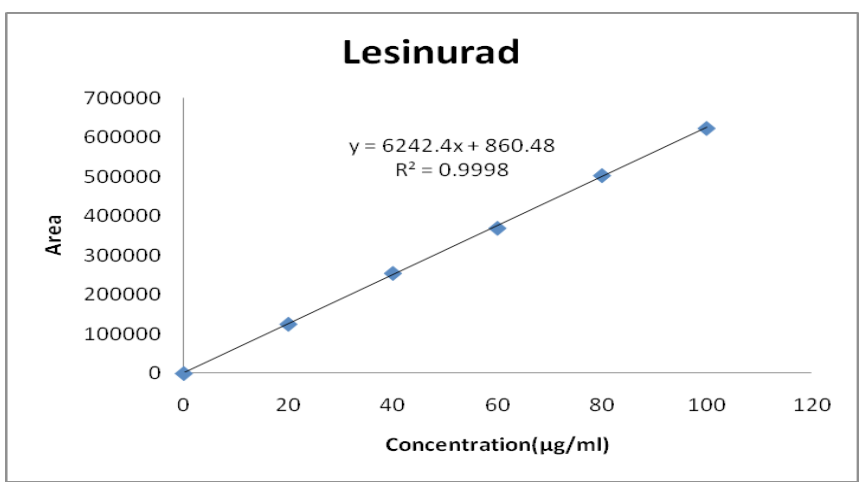

Fig. 5: Calibration graph for lesinurad

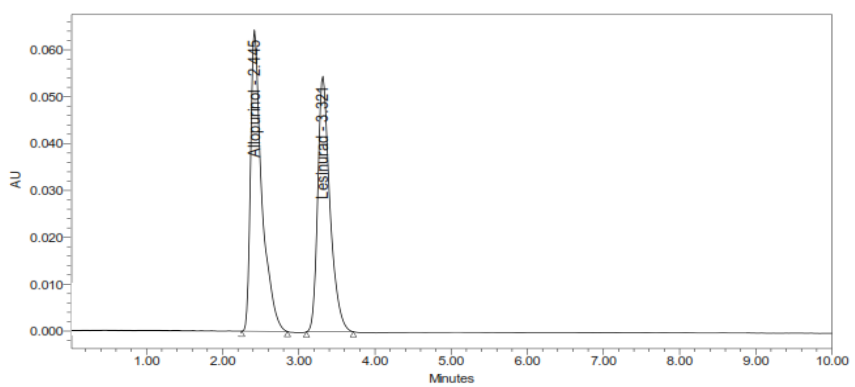

Fig. 6: 50\% Accuracy chromatogram

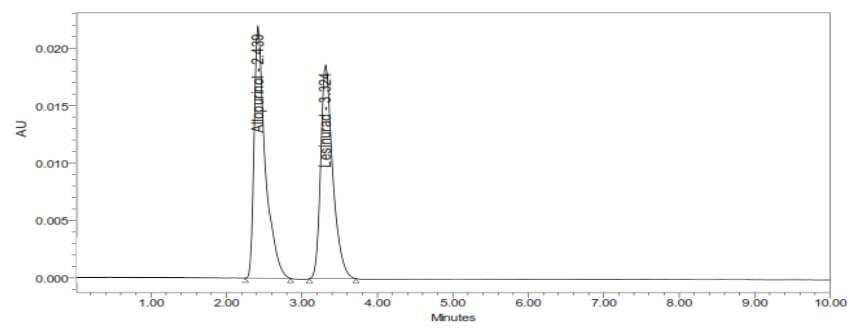

Fig. 7: 100\% Accuracy chromatogram 
Table 7: Accuracy (Recovery) data for allopurinol

\begin{tabular}{lllllll}
\hline & $\begin{array}{l}\text { \% Concentration } \\
\text { (at specification level) }\end{array}$ & $\begin{array}{l}\text { Peak } \\
\text { area }\end{array}$ & $\begin{array}{l}\text { Amount } \\
\text { added } \\
(\mathrm{mg})\end{array}$ & $\begin{array}{l}\text { Amount } \\
\text { found } \\
(\mathrm{mg})\end{array}$ & $\begin{array}{l}\text { Recovery } \\
(\%)\end{array}$ & $\begin{array}{l}\text { Mean recovery } \\
(\%)\end{array}$ \\
\hline \multirow{3}{*}{ Allopurinol } & $50 \%$ & 233682 & 30 & 30.19 & 100.64 & 100.69 \\
& $100 \%$ & 466589 & 60 & 60.29 & 100.48 & 100.96 \\
\\
Lesinurad & $150 \%$ & 703223 & 90 & 90.86 & 100.50 & 100.49 \\
& $50 \%$ & 186179 & 20 & 20.10 & 100.75 & 100.20 \\
\hline
\end{tabular}

${ }^{*}$ Average of three determinations

Table 8: Results of LOD

\begin{tabular}{llll}
\hline Name of drug & Baseline noise $(\mu \mathrm{V})$ & Obtained signal $(\mu \mathrm{V})$ & S/N ratio \\
\hline Allopurinol & 63 & 191 & 3.03 \\
Lesinurad & 63 & 188 & 2.98 \\
\hline \multicolumn{4}{l}{ Table 9: Results of LOQ } \\
\hline Name of drug & \multicolumn{4}{c}{ Baseline noise $(\mu \mathrm{V})$} & Obtained signal $(\mu \mathrm{V})$ & S/N ratio \\
\hline Allopurinol & 63 & 631 & 10.02 \\
Lesinurad & 63 & 629 & 9.98 \\
\hline
\end{tabular}

Table 10: Variations in flow for allopurinol and lesinurad

\begin{tabular}{|c|c|c|c|c|c|}
\hline \multirow[b]{2}{*}{ S. No. } & \multirow[b]{2}{*}{ Drug } & \multirow{2}{*}{$\begin{array}{l}\text { Rate of flow ( } \mathrm{mL} \\
\text { min) }\end{array}$} & \multicolumn{3}{|c|}{ Results of system suitability } \\
\hline & & & USP resolution & USP tailing & USP plate count \\
\hline 1 & & 0.9 & 3.16 & 1.53 & 3587.65 \\
\hline 2 & Allopurinol & 1.0 & 3.16 & 1.53 & 3494.63 \\
\hline 3 & & 1.1 & 3.16 & 1.53 & 3427.86 \\
\hline 1 & & 0.9 & 3.31 & 1.41 & 5348.76 \\
\hline 2 & Lesinurad & 1.0 & 3.16 & 1.40 & 5231.87 \\
\hline 3 & & 1.1 & 2.97 & 1.39 & 5207.38 \\
\hline
\end{tabular}

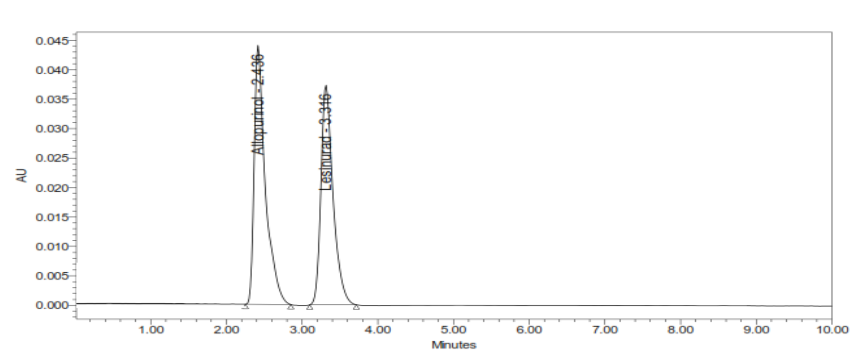

Fig. 8: $150 \%$ Accuracy Chromatogram

\subsubsection{Limit of Quantification ( $L O Q$ )}

The LOQ for allopurinol and lesinurad were found to be 10.02 and 9.98 which is in accepted criteria given in Table 9. This shows that the method is having good system suitability and precision under given set of conditions.

\subsubsection{Robustness}

The standard and samples of allopurinol and lesinurad were injected by changing the conditions of chromatography. There was no significant change in the parameters like resolution, tailing factor, asymmetric factor, and plate count and are in limits (Table 10).

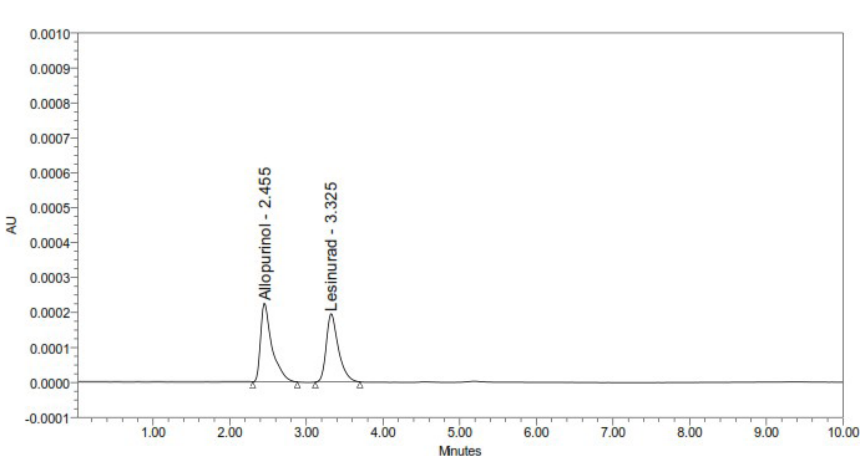

Fig. 9: Chromatogram of Allopurinol, Lesinurad showing LOD

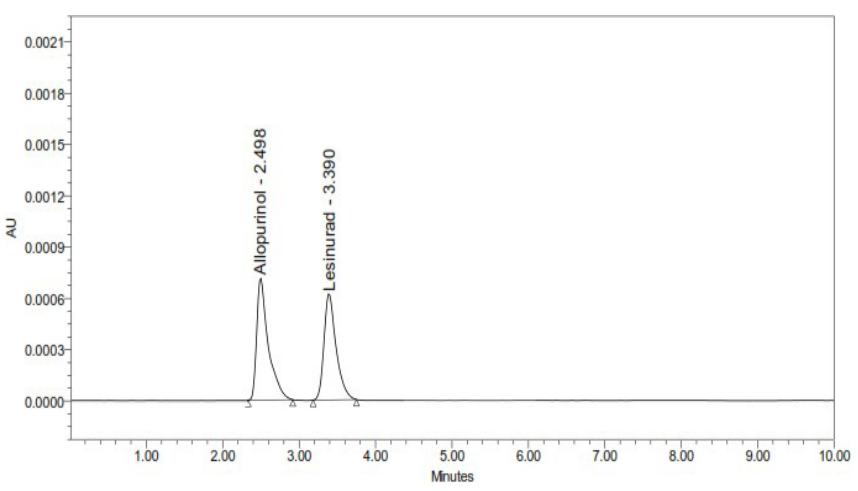

Fig. 10: Chromatogram of allopurinol, lesinurad showing LoQ 
Table 11: Results for the stability of allopurinol and lesinurad

\begin{tabular}{lllll}
\hline & Allopurinol & \multicolumn{3}{c}{ Lesinurad } \\
\cline { 2 - 5 } Sample Name & Area & \% Degraded & Area & \% Degraded \\
\hline Standard & 463442.7 & - & 369747 & - \\
Acid & 447882 & 3.36 & 338774 & 8.38 \\
Base & 444972 & 3.99 & 334928 & 9.42 \\
Peroxide & 436676 & 5.78 & 347222 & 6.09 \\
Thermal & 429847 & 7.25 & 349852 & 5.38 \\
Photo & 441856 & 4.66 & 358733 & 2.98 \\
\hline
\end{tabular}

\subsection{Degradation Studies}

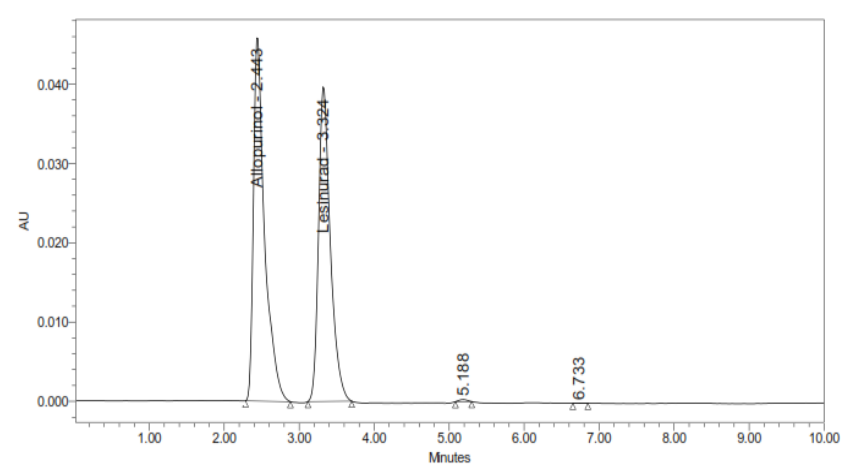

Fig. 11: Acid Degradation Chromatogram

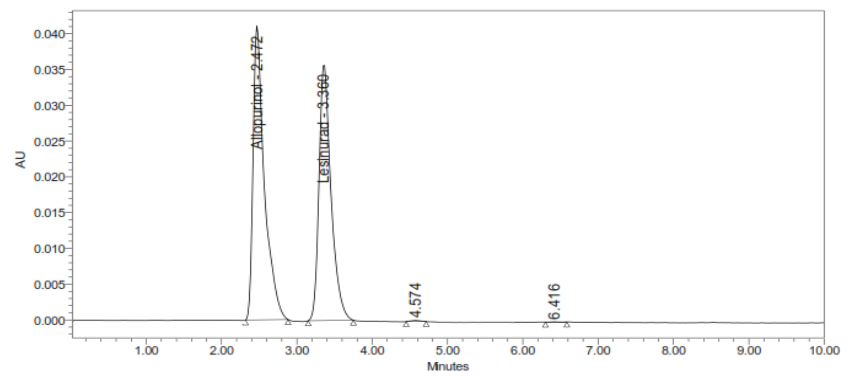

Fig. 12: Base degradation chromatogram

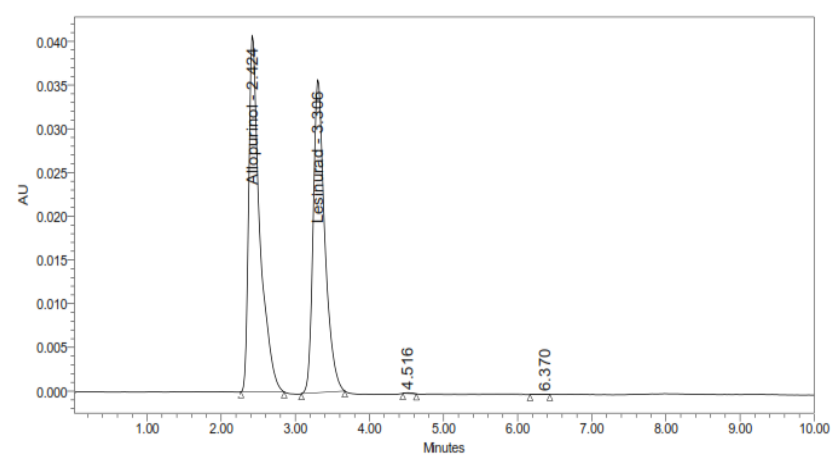

Fig. 13: Peroxide degradation chromatogram

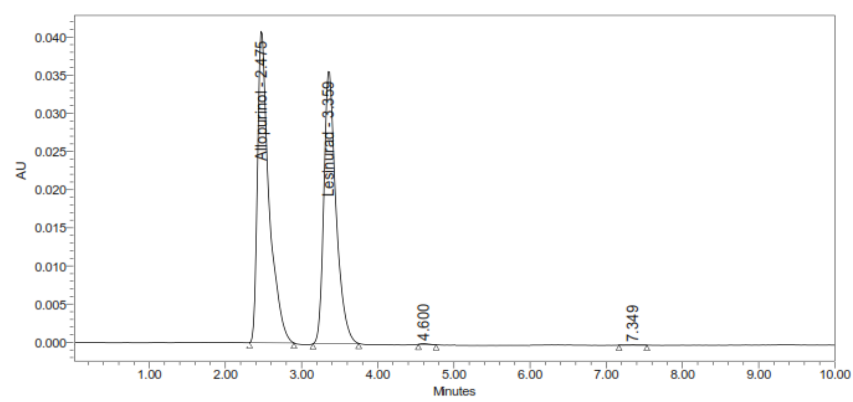

Fig. 14: Photo-degradation chromatogram

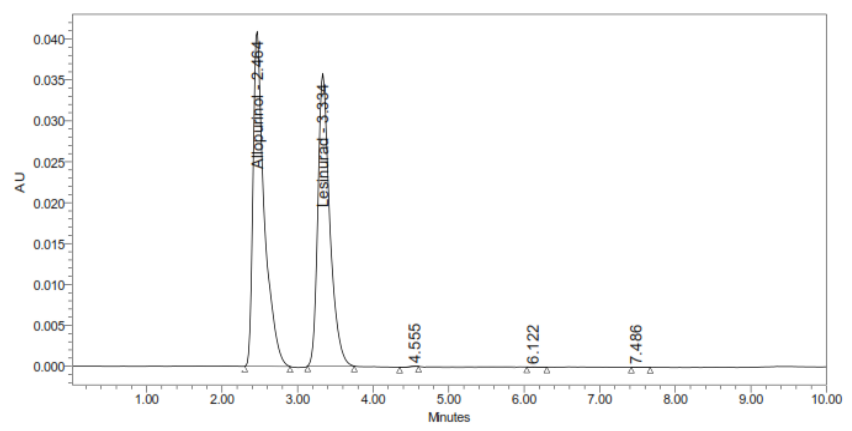

Fig. 15: Thermal degradation chromatogram

\section{DISCUSSION AND CONCLUSION}

In the present developed reverse phase-HPLC method, a satisfactory separation with good peak symmetry was obtained with inertsil ODS $(4.6 \times 250 \mathrm{~mm}, 5 \mathrm{~mm})$ column using mixture of mobile phase containing $0.1 \%$ trifluoro acetic acid buffer and methanol (40:60) at a flow rate of $1 \mathrm{~mL} / \mathrm{min}$. Quantification was achieved at UV detection at $255 \mathrm{~nm}$ based on peak area. The present optimized method was validated according to the guidelines of ICH (Bakshi and Singh, 2002; Breaux et al., 2003; Swartz and Krull, 2018).

For system suitability, the method was validated for linearity, precision, specificity and accuracy, LOD, LOQ, and robustness. The system suitability parameters such as retention time, resolution, tailing, and plate count have shown uniformity and \% RSD was less than 1 and found to be within limits. Hence it was concluded that the system was suitable to perform the assay.

The method was observed to be simple and accurate as the recovery of both the drugs was found to be $>100 \%$. The chromatographic isolation was clear and there was no interference indicating that the method was specific. The LOD and LOQ values of both the drugs are within the desired criteria. The results of degradation studies were $<10 \%$ as the acceptance criteria was NMT $15 \%$. Therefore, the method was also found to be stable. There is no interference of any excipients peaks with standard and analytic peak and hence it proves that the method is selective.

From the results obtained, it is evident that the developed method can be employed to estimate allopurinol 
and lesinurad in other pharmaceutical formulations as well.

\section{REFERENCES}

1. Ahuja S. and Dong M. (2005). Handbook of pharmaceutical analysis by HPLC. Elsevier; 2005.

2. Ahuja S. Rasmussen H. (2011). HPLC method development for pharmaceuticals. Elsevier; 2011.

3. Arellano F, Sacristán JA. (1993). Allopurinol hypersensitivity syndrome: a review. Annals of Pharmacotherapy. (3):337-43.

4. Attia K. A. M., El-Abasawi N. M., El-Olemy A., Abdelazim A. H. (2018). Validated Stability Indicating High Performance Liquid Chromatographic Determination of Lesinurad. J Chromatogr Sci. 56(4):358-366.

5. Baertschi S. W., Alsante K. M., Reed R. A. (2016). Pharmaceutical stress testing: predicting drug degradation. CRC Press.

6. Bakshi M, Singh S. (2002). Development of validated stabilityindicating assay methods- critical review. Journal of pharmaceutical and biomedical analysis. 28(6):1011-40.

7. Bardin T, Keenan RT, Khanna PP, Kopicko J, Fung M, Bhakta N, Adler S. (2017). Storgard C, Baumgartner S, So A. Lesinurad in combination with allopurinol: a randomised, doubleblind, placebo-controlled study in patients with gout with inadequate response to standard of care (the multinational CLEAR 2 study). Annals of the rheumatic diseases. 76(5): 811-20.

8. $\quad$ Blessy M. R., Patel R. D., Prajapati P. N., Agrawal Y. K. (2014). Development of forced degradation and stability indicating studies of drugs-A review. Journal of pharmaceutical analysis. 4(3):159-65.

9. Borstad G. C., Bryant L. R., Abel M. P., Scroggie D. A., Harris M. D., Alloway J. A. (2004). Colchicine for prophylaxis of acute flares when initiating allopurinol for chronic gouty arthritis, The Journal of rheumatology. 31(12): 2429-32.

10. Breaux J, Jones K, Boulas P. (2003). Analytical methods development and validation. Pharm. Technol.6-13.

11. Connors K. A. (2007). A textbook of pharmaceutical analysis. John Wiley \& Sons.

12. Dastiagiriamma C. K., Sowjanya H. M., Hemalatha K. (2018). Simultaneous estimation of Lesinurad and Allopurinol by using reverse phase high performance liquid chromatography in API and marketed formulation. Innovat International Journal of Medical and Pharmaceutical Sciences. Volume 3, Supp 1.
13. Ermer J. (2001). Validation in pharmaceutical analysis. Part I: An integrated approach. Journal of pharmaceutical and biomedical analysis. 24(5-6): 755-67.

14. Goicoechea M., de Vinuesa S. G., Verdalles U., Ruiz-Caro C., Ampuero J., Rincón A., Arroyo D., Luño J. (2010). Effect of allopurinol in chronic kidney disease progression and cardiovascular risk. Clinical Journal of the American Society of Nephrology. 5(8): 1388-93.

15. Hoy S. M. (2016). Lesinurad: First global approval. Drugs. 76(4): 509-16.

16. Ngwa G. (2010). Forced degradation as an integral part of HPLC stability-indicating method development. Drug delivery technology. 10(5): 56-9.

17. Perez-Ruiz F., Sundy J. S., Miner J. N., Cravets M., Storgard C. (2016). Lesinurad in combination with allopurinol: results of a phase 2, randomised, double-blind study in patients with gout with an inadequate response to allopurinol. Annals of the rheumatic diseases. 75(6): 1074-80

18. Revathi S., Reddy G. R., Narendra N. K., Kirankumar V. (2016) Development and validation of RP-HPLC method for simultaneous estimation of allopurinol and alphalipoicacid in bulk and tablet dosage form. Int. J. of Pharmacy and Analytical Research, Vol-5(4): 602-612.

19. Reynolds D. W., Facchine K. L., Mullaney J. F., Alsante K. M., Hatajik T. D., Motto M. G. (2002). Conducting forced degradation studies. Pharmaceutical technology. 48-56.

20. Snyder L. R., Quarry M. A. (1987). Computer simulation in HPLC method development. Reducing the error of predicted retention times. Journal of liquid chromatography. 10(89): 1789-820.

21. Stamp L. K. (2014). Safety profile of anti-gout agents: an update. Current opinion in rheumatology. 26(2): 162-8.

22. Swartz M. E. (2018). Krull IS. Analytical method development and validation. CRC Press.

How to cite this article: Sayma K., Ayesha B. K. \& Ramakrishna D (2019). Development and Validation of Reverse Phase HPLC Method for Simultaneous Estimations of Allopurinol and Lesinurad in its API and Pharmaceutical Dosage Form. Int. J. Appl. Pharm. Sci. Res. 4(4): 50-57. doi: https://doi.org/10.21477/ijapsr.4.4.1

Source of Support; Nil

Conflict of Interest: None declared. 